Global Conferences Series:

Sciences and Technology (GCSST), Volume 5, 2020

Seminar Nasional I Baristand Industri Padang (Semnas I BIPD)

DOI: https://doi.org/10.32698/GCS-SNIIBIPD3441

\title{
Optimation of poly aluminium chloride (PAC) and activated carbon on the laboratory wastewater treatment process in pretreatment sedimentation pond
}

\section{Optimasi poly aluminium chloride (PAC) dan arang aktif terhadap proses pengolahan air limbah laboratorium di bak pengendap awal}

\author{
Masmulki Daniro Jyoti ${ }^{1}$, Karim Abdullah ${ }^{1}$, Tri Susanto ${ }^{2}$ \\ ${ }^{1}$ Baristand Industri Bandar Lampung, Indonesia \\ ${ }^{2}$ Baristand Industri Palembang, Indonesia \\ E-mail: daaniiroo@gmail.com
}

\begin{abstract}
The operational process of the service laboratory produces wastewater that cannot be disposed directly but must be treated before being discharged into the environment. The optimal treatment process needs to be determined based on the characteristics of the wastewater produced. This study will determine the optimization of the laboratory waste treatment process in the initial settling basin by comparing the addition of coagulants and activated carbon. Wastewater generated from the operational process of the laboratory was collected from the initial settling basin, then its characteristics were determined including $\mathrm{pH}$, turbidity, TSS, TDS, surfactane as MBAS, ammonia, Total Fe and Mn. Wastewater was added with Poly Aluminum Chloride (PAC) coagulant with a concentration of 50, 100, 200, and $300 \mathrm{ppm}$. As a comparison, the addition of 20, 40,60 and 80 grams of activated carbon was also carried out in one liter of wastewater. The best results were the addition of $50 \mathrm{ppm}$ PAC was able to reduce the turbidity value up to $87.2 \%$, TSS $83.3 \%$, Mn metal $70.57 \%$ and Fe $60.11 \%$. While the addition of 80 grams of activated carbon is able to restore the $\mathrm{pH}$ value to neutral and reduce the MBAS content to $83.62 \%$. Furthermore, the addition of PAC and activated charcoal has no significant effect on reducing levels of ammonia and TDS. The results showed that the addition of PAC can be done in the initial basin and combined with the addition of activated carbon in the subsequent processing basin.
\end{abstract}

Keywords: PAC; activated carbon; laboratory wastewater; coagulant

\begin{abstract}
Abstrak: Proses operasional laboratorium penguji menghasilkan limbah cair yang tidak dapat dibuang langsung namun harus diolah terlebih dahulu sebelum dibuang ke lingkungan. Proses pengolahan yang optimal perlu ditentukan berdasarkan pada karakteristik limbah cair yang dihasilkan. Penelitian ini akan menentukan optimalisasi proses pengolahan limbah laboratorium pada bak pengendap awal dengan membandingkan antara penambahan koagulan dan arang aktif. Air limbah yang dihasilkan dari proses operasional laboratorium ditampung di bak pengendap awal, lalu ditentukan karakteristiknya meliputi $\mathrm{pH}$, kekeruhan, TSS, TDS, surfaktan sebagai MBAS, ammonia, logam Fe total dan Mn total. Air limbah ditambahkan koagulan Poly Alumunium Chloride (PAC) dengan konsentrasi 50, 100, 200, dan 300 ppm. Sebagai pembanding juga dilakukan penambahan arang aktif sebanyak 20, 40, 60 dan 80 gram dalam 1 liter air limbah. Hasil terbaik yaitu penambahan PAC 50 ppm mampu menurunkan nilai kekeruhan hingga $87,2 \%$, TSS $83,3 \%$, Mn 70,57\% dan Fe 60,11\%. Sedangkan penambahan arang aktif 80 gram mampu mengembalikan nilai $\mathrm{pH}$ menjadi netral dan menurunkan kandungan MBAS hingga 83,62 \%. Lebih lanjut, penambahan PAC dan arang aktif tidak berpengaruh signifikan terhadap penurunan kadar ammonia dan TDS. Hasil penelitian menunjukkan penambahan PAC dapat dilakukan pada bak awal dan dikombinasikan dengan penambahan arang aktif pada bak pengolahan selanjutnya.
\end{abstract}

Kata kunci: PAC; arang aktif; limbah laboratorium; koagulan

Copyright (C) 2020, the Authors. Published by Redwhite Press.

This is an open access article under the CC BY-NC license

(http://creativecommons.org/licenses/by-nc/4.0). 


\section{PENDAHULUAN}

Laboratorium Penguji Baristand Industri Bandar Lampung adalah salah satu laboratorium yang telah terakreditasi oleh Komite Akreditasi Nasional untuk berbagai macam jenis sampel seperti air bersih, air limbah, air minum dalam kemasan, beberapa jenis pupuk serta tepung tapioka. Dalam berjalannya laboratorium dihasilkan limbah cair yang harus diolah terlebih dahulu sebelum dibuang ke lingkungan. Untuk melakukan pengolahan dibutuhkan instalasi pengolahan air limbah yang selanjutnya disebut dengan IPAL (Instalasi Pengolah Air Limbah).

Instalasi pengolahan air limbah merupakan sarana untuk melakukan pengolahan air limbah hingga memenuhi persyaratan ambang batas yang telah ditentukan sebelum dibuang ke perairan. Proses yang dilakukan disesuaikan dengan jenis dan karakterisitik limbah yang akan diolah sehingga akan dihasilkan efektifitas dan efisiensi dalam penggunaan bahan, peralatan dan juga tenaga kerja.

Pengolahan limbah sangatlah penting untuk menjaga lingkungan dari pencemaran akibat dari air limbah. Selain itu, IPAL menjadi salah satu kewajiban yang harus dipenuhi oleh laboratorium penguji apabila ingin ditunjuk sebagai laboratorium lingkungan oleh Kementerian Kehutanan dan Lingkungan hidup. Keberadaan IPAL menunjukan bahwa Laboratorium penguji memiliki komitmen yang tinggi dalam mengurangi pencemaran akibat aktifitas yang di lakukan dalam laboratorium.

Beberapa jenis pengolahan limbah telah diterapkan untuk mengolah limbah yang dihasilkan oleh laboratorium seperti pengolahan dengan teknik koagulasi dan adsorpsi yang mampu menurunkan kadar $\mathrm{COD}, \mathrm{Fe}$ dan juga $\mathrm{Pb}$ (Audina, 2017). Penerapan metode filtrasi dan adsorpsi yang mampu menurunkan kadar BOD, COD dan TSS limbah cair (Sulistyanti, et. al., 2018). Pengolahan dengan kombinasi elektrokoagulasi, filtrasi dan pengikatan logam menggunakan asam jawa (Fadhilah, 2018). Teknik adsorpsi dan Pretreatment Netralisasi dan Koagulasi dengan menggunakan Poly Alum Chlorida (PAC) mampu menurunkan kadar TDS, Cr dan juga Pb (Nurhayati, dkk., 2018)

Pengolahan limbah deterjen telah dilakukan dengan menggunakan metode koagulasi-flokulasi menggunakan koagulan kapur dan PAC dengan parameter yang diuji adalah BOD dan COD. Didapatkan hasil bahwa koagulan kapur lebih optimal dibandingkan dengan penambahan PAC pada konsentrasi yang sama (Rahimah, et. al., 2016).

Arang aktif dapat digunakan sebagai zat yang mampu menyerap kandungan logam terlarut dalam air limbah, seperti penelitian yang dilakukan untuk mengurangi kandungan logam Crom dengan menggunakan arang aktif yang diaktivasi dengan berbagai teknik menunjukan bahwa arang aktif mampu menurunkan kandungan krom antara 22 - 99\% (Rosalina, et. al., 2016). Penambahan arang aktif juga mampu mengembalikan nilai pH air limbah dari 5 menjadi 7,4 pada limbah tahu (Mangiwa, et. al., 2020). Lebih lanjut arang aktif mampu menurunkan kandungan Fe antara 10,41-58\%, Mn 9,51-48,9 dan menaikkan $\mathrm{pH}$ dari 5,8 menjadi 7,6 (Viena, et. al., 2020).

Arang aktif juga telah digunakan untuk menurunkan kadar fosfat dan deterjen dalam limbah domestik dengan teknik filtrasi upflow. Hal penelitian menunjukan bahwa penurunan kandungan deterjen sebesar 62,78\% dan fosfat sebesar 67,71\% (Artiyani dan Firmansyah, 2016). Penelitian lain menunjukkan bahwa arang aktif mampu menurunkan deterjen hingga 90\% (Hidayat dan Cahyono, 2019).

Dari paparan yang telah dijabarkan di atas maka tahapan awal dari pengolahan limbah adalah menentukan karakteristik awal dari limbah yang akan diolah meliputi nilai pH, COD, TDS, TSS, minyak lemak, deterjen dan juga beberapa logam utama seperti Fe, Mn. Setelah itu dilakukan penentuan konsentrasi koagulan yang tepat sehingga proses pengendapan dapat berlangsung dengan cepat dan efisien. Selanjutnya dilakukan juga pengolahan dengan menggunakan arang aktif sebagai pembanding.

Poli Aluminum Klorida (PAC) memiliki rumus kimia $\mathrm{Al}_{2}(\mathrm{OH})_{6-n} \mathrm{Cln}_{\mathrm{xH}} \mathrm{O}(\mathrm{n}=1-5)$ merupakan salah satu jenis koagulan yang telah digunakan secara umum pada pengolahan air dan air limbah karena memiliki beberapa keunggulan seperti lebih aman karena tidak akan menurunkan $\mathrm{pH}$ secara tajam saat beraksi dengan air. Hal tersebut terjadi karena PAC hanya melepaskan 1 kation $\mathrm{H}^{+}$dibandingkan dengan alumunium sulfat yang melepaskan 6 ion $\mathrm{H}^{+}$, proses lebih cepat dibandingkan dengan tawas dan aluminium sulfat (Budiman, et. al., 2008).

Arang aktif adalah suatu padatan berpori yang mengandung 85-95\% karbon, yang dihasilkan dari proses pemanasan pada suhu tinggi terhadap zat yang mengandung karbon. Arang aktif memiliki luas permukaan antara 300-3500 m²/gram. Arang aktif memiliki kemampuan absorbsi hingga 25-100\% dari beratnya karena adanya struktur pori internal (Sembiring and Sinaga, 2003). 


\section{METODE}

Alat dan Bahan

Peralatan yang digunakan meliputi Overhead Stirrer (OHS 100), dan Peralatan Gelas. Untuk peralatan uji yang digunakan adalah Neraca Analitik (Shimadzu), Turbidimeter (Hach TL2350), Oven Listrik (Memmert), Waterbath (Memmert), Spektrofotometer DR 3900, Atomic Absorption Spectrofotometer (Shimadzu) dan seperangkat pompa vakum. Bahan kimia untuk melakukan pengujian meliputi reagent COD Kit (Hach), Nessler Reagent Kit (Hach), Air Demineralisasi, Kertas Saring (Whatman), $\mathrm{HNO}_{3}$ (Merck).

\section{Pelaksanaan Penelitian}

Penelitian dilakukan pada bulan September-Oktober tahun 2020 berlokasi di Laboratorium Proses dan Pengujian Baristand Industri Bandar Lampung. Air limbah dari seluruh laboratorium yang ada dikumpulkan dalam bak penampungan awal. Sampel diambil sebanyak 10 Liter, lalu dihomogenkan. Kemudian dipersiapkan 9 gelas kimia, lalu masing-masing diisi dengan 1 Liter air limbah. Pada gelas kimia pertama ditambahkan secara perlahan larutan PAC 20\% sebanyak 0,25 ml sambil diaduk dengan menggunakan overhead stirer selama 5 menit dengan kecepatan $50 \mathrm{rpm}$. Setelah selesai, larutan didiamkan untuk dilakukan proses analisis. Dilakukan proses tersebut pada gelas kimia lainnya dengan penambahan PAC berturut-turut $0,5 \mathrm{ml} ; 1 \mathrm{ml}$ dan 1,5 ml. Selanjutnya dilakukan juga proses pengolahan dengan menambahkan arang aktif dengan sebanyak 20 gr, 40 gr, 60 gr dan 80 gr. Didiamkan masing-masing proses selama 1 jam agar terjadi pengendapan sempurna. Selanjutnya dilakukan analisa pH, Ammonia, TDS, TSS, Kekeruhan, MBAS, Logam Fe dan Logam Mn.

\section{HASIL DAN PEMBAHASAN}

Nilai pH diukur berdasarkan pada metode SNI 06-6989.11-2004, Hasil pengukuran disajikan dalam grafik Gambar 1.

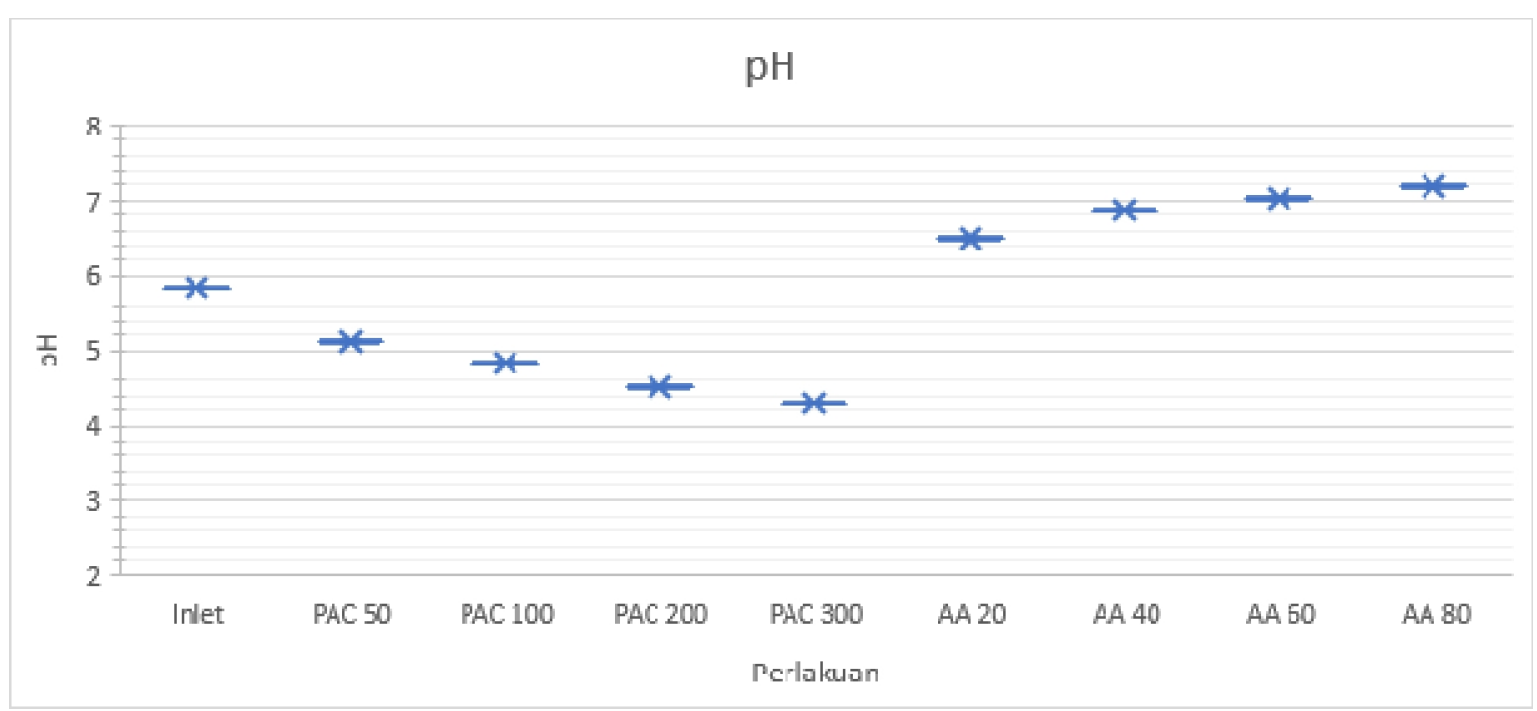

Gambar 1. Nilai pH pada berbagai perlakuan menggunakan PAC dan AA

Berdasarkan grafik Gambar 1, peningkatan konsentrasi PAC menghasilkan nilai $\mathrm{pH}$ yang semakin menurun yaitu pada konsentrasi PAC 50 ppm memiliki nilai pH 5,11, menurun menjadi 4,3 pada konsentrasi PAC 300 ppm. Hal ini sesuai dengan yang dilakukan oleh (Budiman et al, 2008) bahwa semakin besar kadar PAC yang ditambahkan dalam sampel air, semakin banyak ion $\mathrm{H}+$ yang dilepaskan dalam air. Seperti ditunjukan melalui reaksi sebagai berikut:

$$
\left[\mathrm{Al}_{2}(\mathrm{OH})_{3}\right]^{+++}+3 \mathrm{H}_{2} \mathrm{O} \longrightarrow 2 \mathrm{Al}(\mathrm{OH})_{3}+3 \mathrm{H}^{+}
$$

Menurut (Gozan, dkk., 2009) penggunaan koagulan untuk proses pengendapan akan menurunkan $\mathrm{pH}$. Hal ini juga diperkuat oleh hasil penelitian yang dilakukan oleh (Manahan, 1994) bahwa pada umumnya penggunaan koagulan untuk proses pengendapan akan menurunkan $\mathrm{pH}$. Namun penurunan yang terjadi tidak terlalu drastis. 
Pada penambahan arang aktif komersil mampu meningkatkan nilai $\mathrm{pH}$ dari 6,49 pada penambahan 20 gram arang aktif menjadi 7,17 pada penambahan 90 gram. Peningkatan nilai $\mathrm{pH}$ ini terjadi dikarenakan kemampuan daya ikat arang aktif yang berpori terhadap ion-ion $\mathrm{H}+$ yang terkandung dalam sampel. Arang aktif merupakan salah satu adsorben yang banyak digunakan karena telah terbukti mempunyai kemampuan adsorpsi yang besar terhadap bau, zat warna, zat- zat organik, ion- ion logam seperti Al, Fe (Nurhasni, et al., 2012) dan fenol (Pambayun et al, 2013).

Hasil pengukuran parameter ammonia yang dilakukan dengan metode Nessler, menghasilkan data seperti yang dapat dilihat pada Gambar 2. Pada grafik diatas menunjukkan bahwa, dengan penggunaan koagulan PAC dapat menurunkan kandungan ammonia dalam air limbah pada penambahan PAC sebesar $0,25 \mathrm{ml}$ dan $0,5 \mathrm{ml}$ dengan penurunan sebesar 51,27\%. Penambahan PAC dosis $1 \mathrm{ml}$ dan 1,5 hanya mampu menurunkan kadar ammonia sebesar 30,7\%. Menurut penelitian (Said, 2009) menunjukan bahwa dosis yang efektif untuk menurunkan ammonia berkisar antara $0,5-4 \mathrm{gr} /$ liter dengan efisiensi penurunan sebesar $62 \%$ maksimal pada dosis $4 \mathrm{gr} / \mathrm{liter}$.

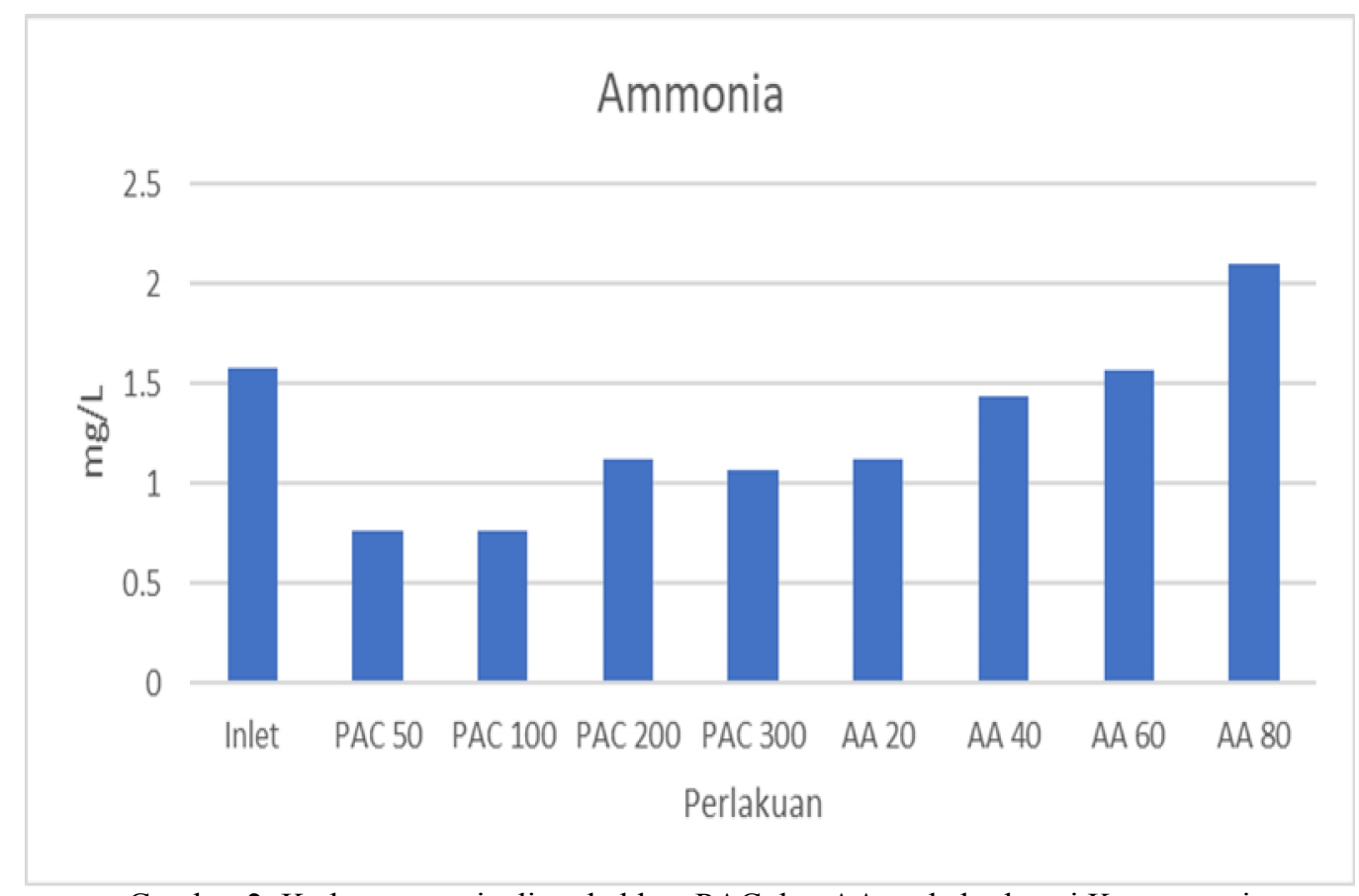

Gambar 2. Kadar ammonia ditambahkan PAC dan AA pada berbagai Konsentrasi

Pengukuran nilai Kekeruhan dilakukan dengan menggunakan alat turbidimeter, dan didapatkan grafik seperti Gambar 3. Secara garis besar pada grafik diatas menunjukkan bahwa, penambahan koagulan PAC cukup efektif dalam menurunkan nilai kekeruhan pada air limbah dengan kisaran efisiensi sebesar 75,53 $87,2 \%$ dari kondisi nilai awal kekeruhan air limbah. Penelitian lain juga menunjukkan bahwa semakin besar kadar PAC yang ditambahkan, turbiditas larutan menjadi semakin rendah (Budiman, et al, 2008). Sedangkan penambahan arang aktif hanya efektif dengan dosis penambahan sebesar $40 \mathrm{gr} / 100 \mathrm{ml}$ sampel dengan ratarata penurunan 19,25 - 44,04\%. Hal ini dapat disebabkan karena kandungan terlarut arang aktif yang ikut mempengaruhi kekeruhan pada sampel. 


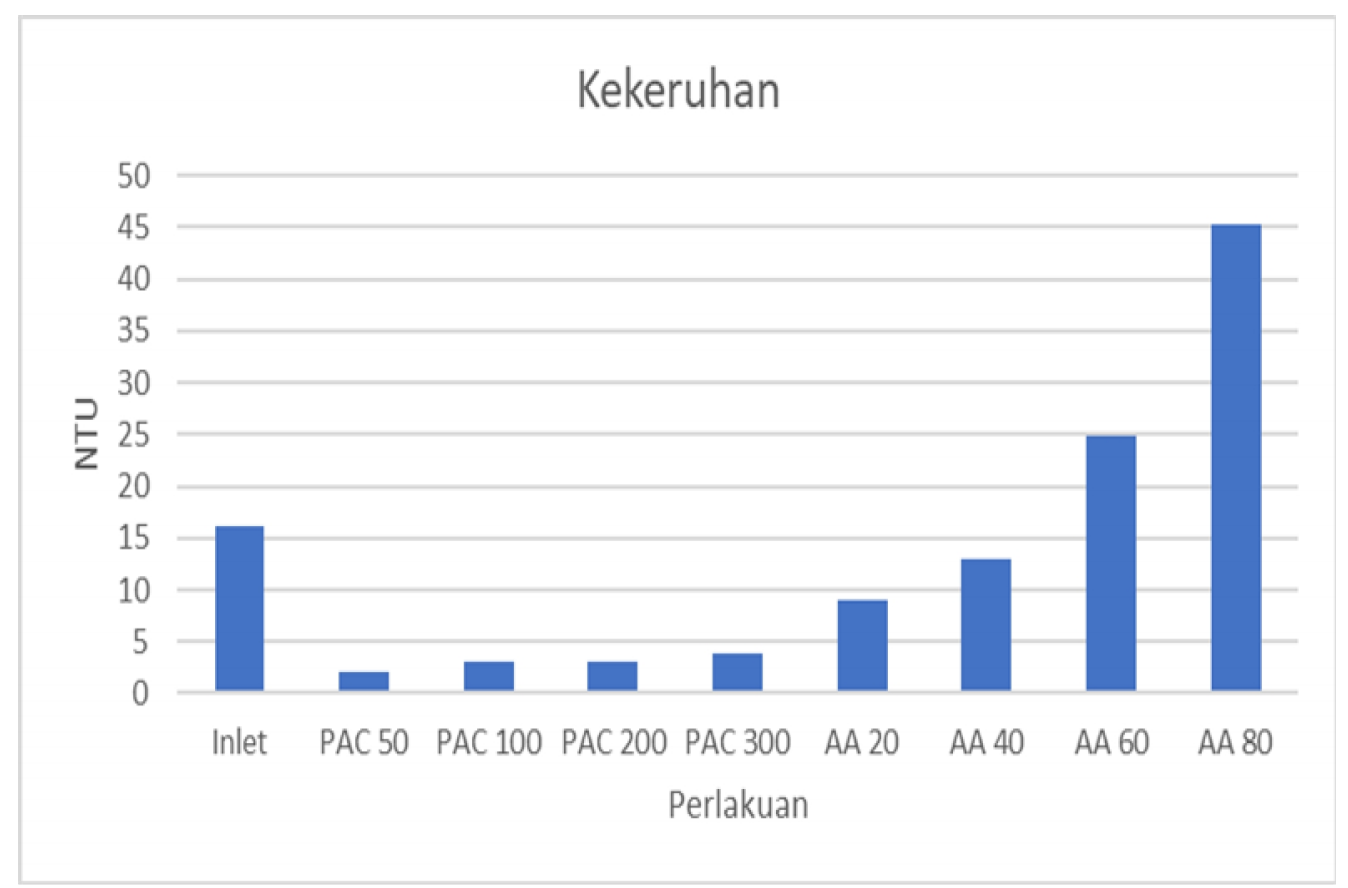

Gambar 3. Nilai Kekeruhan pada berbagai perlakuan penambahan PAC dan AA

Kadar Surfaktan yang diukur sebagai MBAS dapat dilihat pada Gambar 4. Secara garis besar pada grafik diatas menunjukkan bahwa, dengan menggunakan koagulan PAC maupun Arang aktif sangat efektif untuk menurunkan kandungan surfaktan dalam air limbah. Pada perlakuan penambahan koagulan PAC, persentase penurunan sebesar 55,19-71,32\%. Hal tersebut karena surfaktan ikut berikatan dengan PAC dan mengendap sehingga nilainya menjadi turun. Sedangkan saat menggunakan arang aktif didapatkan efektifitas penurunan lebih baik dibandingkan dengan penambahan PAC dengan kisaran 69,53 - 82,97\%. Hal tersebut menunjukan arang aktif yang berpori mampu menyerap surfaktan dengan lebih baik dan menyimpannya di dalam pori-pori.

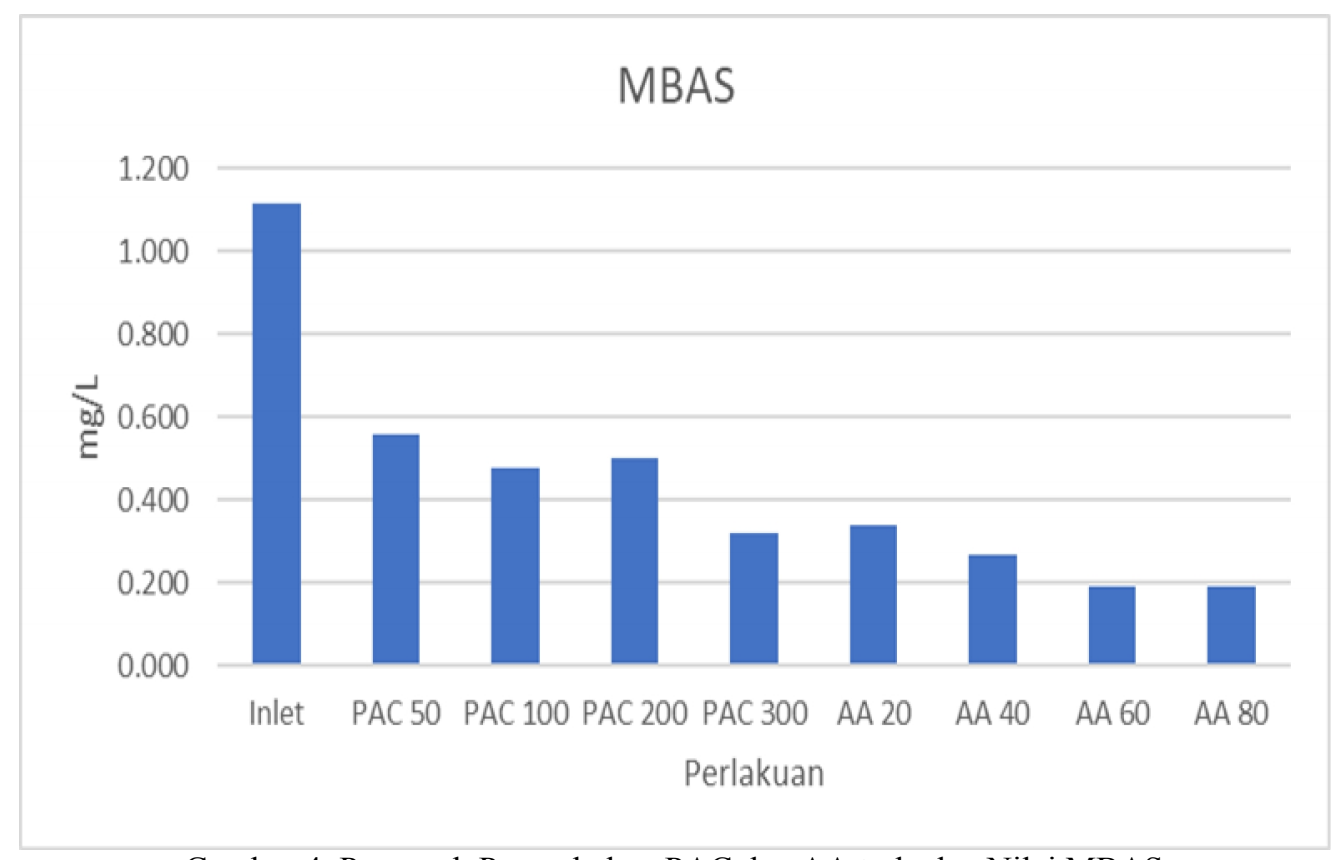

Gambar 4. Pengaruh Penambahan PAC dan AA terhadap Nilai MBAS 
Parameter logam yang diukur pada penelitian ini adalah logam Fe dan $\mathrm{Mn}$, hasil pengukuran dapat dilihat pada grafik Gambar 5 dan 6. Hasil analisa pengaruh penambahan PAC dan arang aktif pada berbagai konsentrasi terhadap kadar Fe dapat dilihat pada Gambar 5.

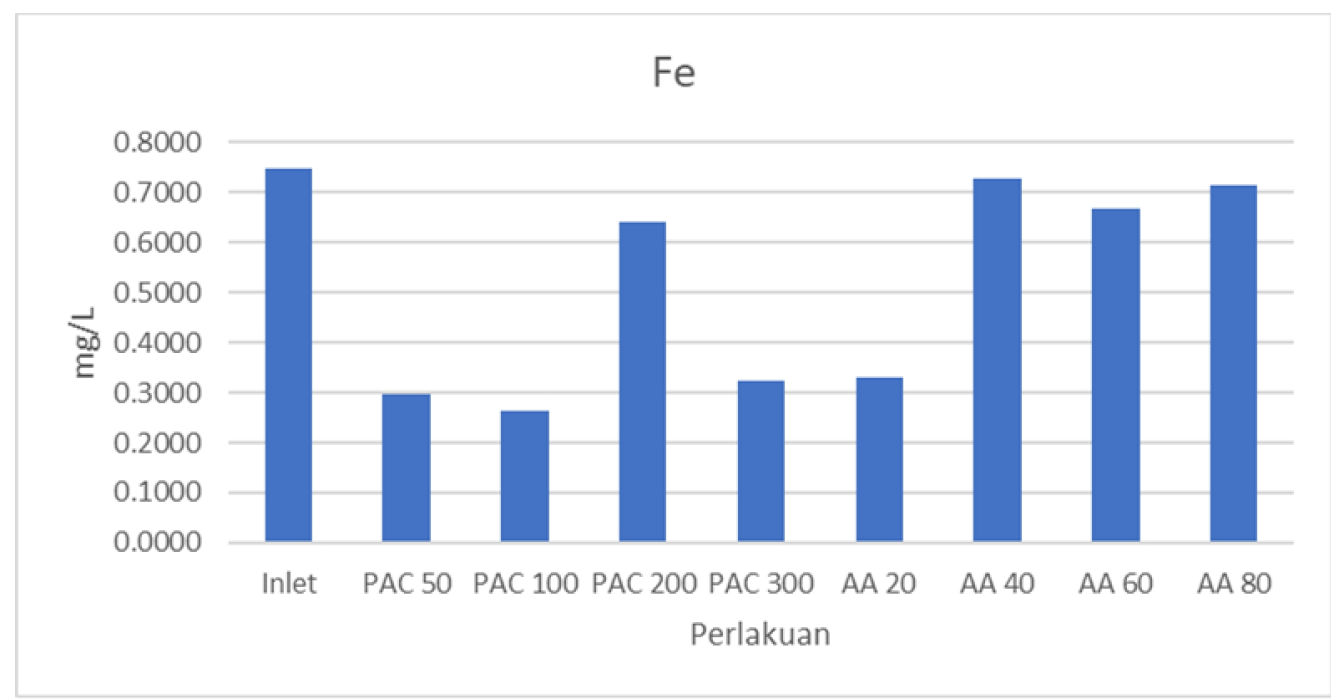

Gambar 5. Pengaruh Penambahan PAC dan AA terhadap kadar logam Fe

Pada grafik menunjukan bahwa penambahan PAC mampu menurunkan kadar logam Fe dengan range antara 14,4-64,7\%. Logam Fe akan berikatan dengan PAC lalu mengendap sehingga nilainya dapat turun. Sedangkan penambahan arang aktif hanya efektif untuk menurunkan kadar Fe pada konsentrasi arang aktif 20 gram yang mampu menurunkan hingga 55,7\%. Hal ini berkorelasi dengan penelitian (Fajarwati, 2012) yang menunjukkan bahwa karbon akif mampu menurunkan logam Fe pada pengolahan air tanah sebesar $59,64 \%$.

Hasil analisa pengaruh penambahan PAC dan arang aktif pada berbagai konsentrasi terhadap kadar Mn dapat dilihat pada Gambar 6. Pada grafik tersebut menunjukkan bahwa penambahan PAC mampu menurunkan kandungan logam $\mathrm{Mn}$ antara 65,5-86,7\%. Hal tersebut menunjukan bahwa PAC mampu berikatan kuat dengan Logam Mn menjadi flok dan mengendap. Sedangkan penambahan arang aktif mampu menurunkan kadar logam Mn antara 34,8 - 62,9\%. Dari data tersebut menunjukan bahwa PAC lebih efektif dalam menurunkan kadar Mn dibandingkan dengan arang aktif.

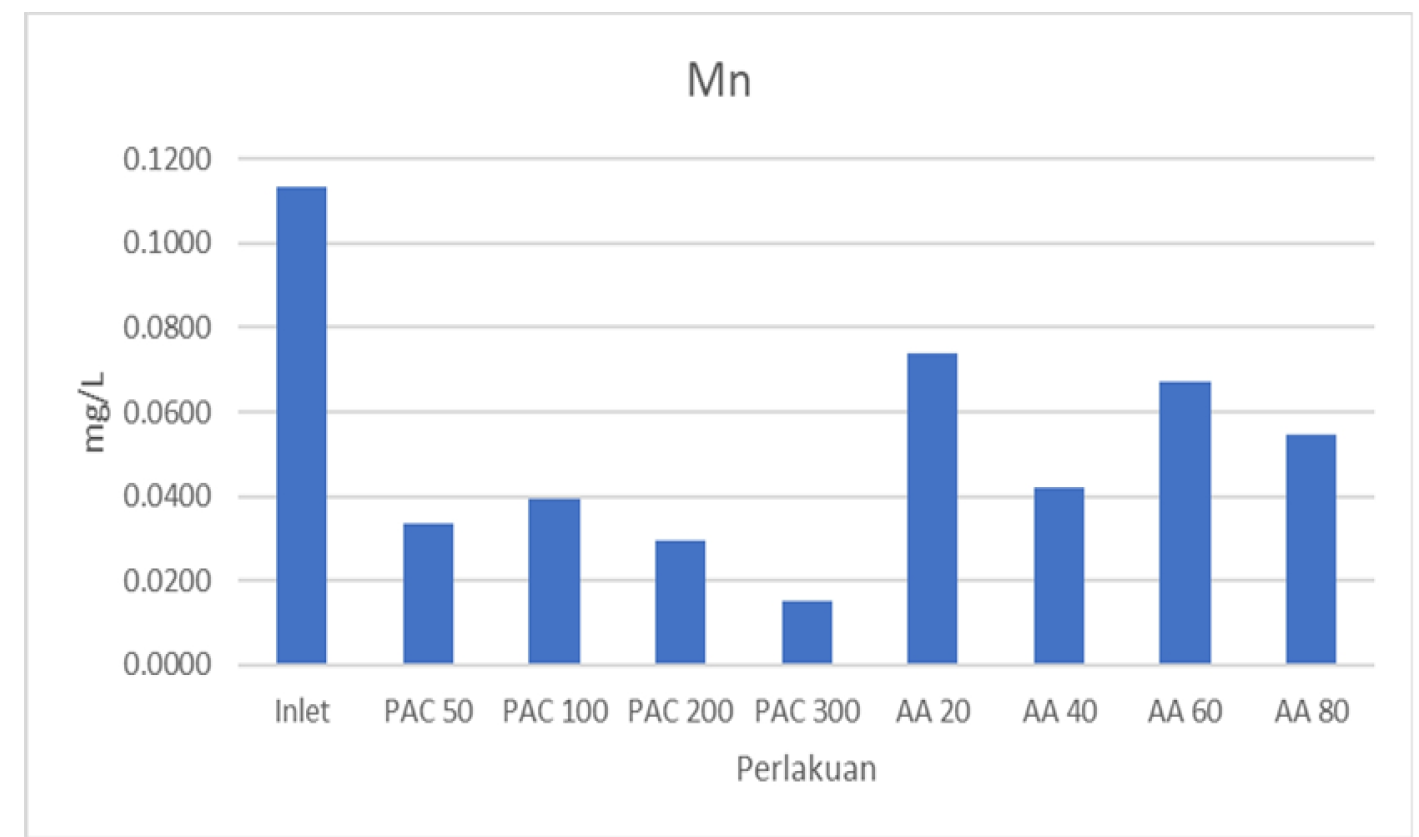

Gambar 6. Pengaruh Penambahan PAC dan AA terhadap kadar Mn Pada Air Limbah 
Hasil pengukuran nilai TSS (Total Suspended Solid) dapat dilihat pada Gambar 7. berikut ini.

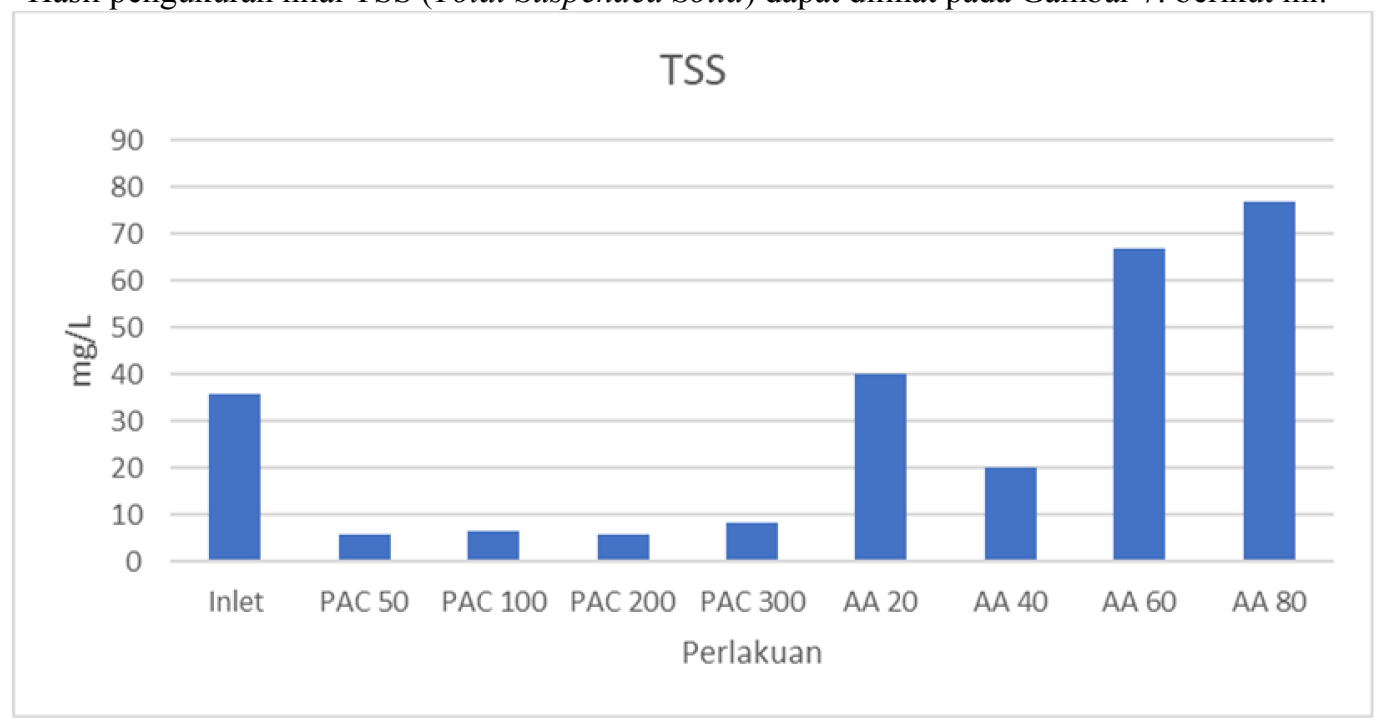

Gambar 7. Pengaruh Penambahan PAC dan AA Terhadap Nilai TSS Air Limbah

Berdasarkan grafik diatas, dapat dilihat bahwa penambahan PAC lebih efektif dalam menurunkan kandungan TSS dengan range antara 76,4-83,3\%. Sedangkan arang aktif tidak dapat menurunkan kandungan TSS, bahkan meningkatkan kandungannya. Hal tersebut karena ada bagian pada arang aktif yang tidak mengendap sehingga menjadikan nilainya bertambah. Pada penambahan PAC, Padatan Tidak terlarut akan diikat oleh PAC menghasilkan koagulan, lalu setelah itu akan mengendap sehingga kandungan TSS akan berkurang.

Pengukuran nilai TDS (Total Dissolved Solid) dilakukan dan hasilnya disajikan pada grafik Gambar 8. Dari grafik dapat dilihat bahwa penambahan PAC dan arang aktif tidak mampu menurunkan nilai TDS. Hal tersebut karena pada saat penambahan PAC, akan ada kation dan anion dari PAC yang belum bereaksi dan akan menjadi zat tak terlarut. Semakin besar penambahan PAC maka nilai TDS nya semakin besar. Begitu juga dengan penambahan arang aktif, arang aktif akan menjadi partikel-partikel yang larut dalam air sehingga meningkatkan nilai TDS nya. Semakin besar arang aktif yang ditambahkan, maka semakin besar nilai TDS nya.

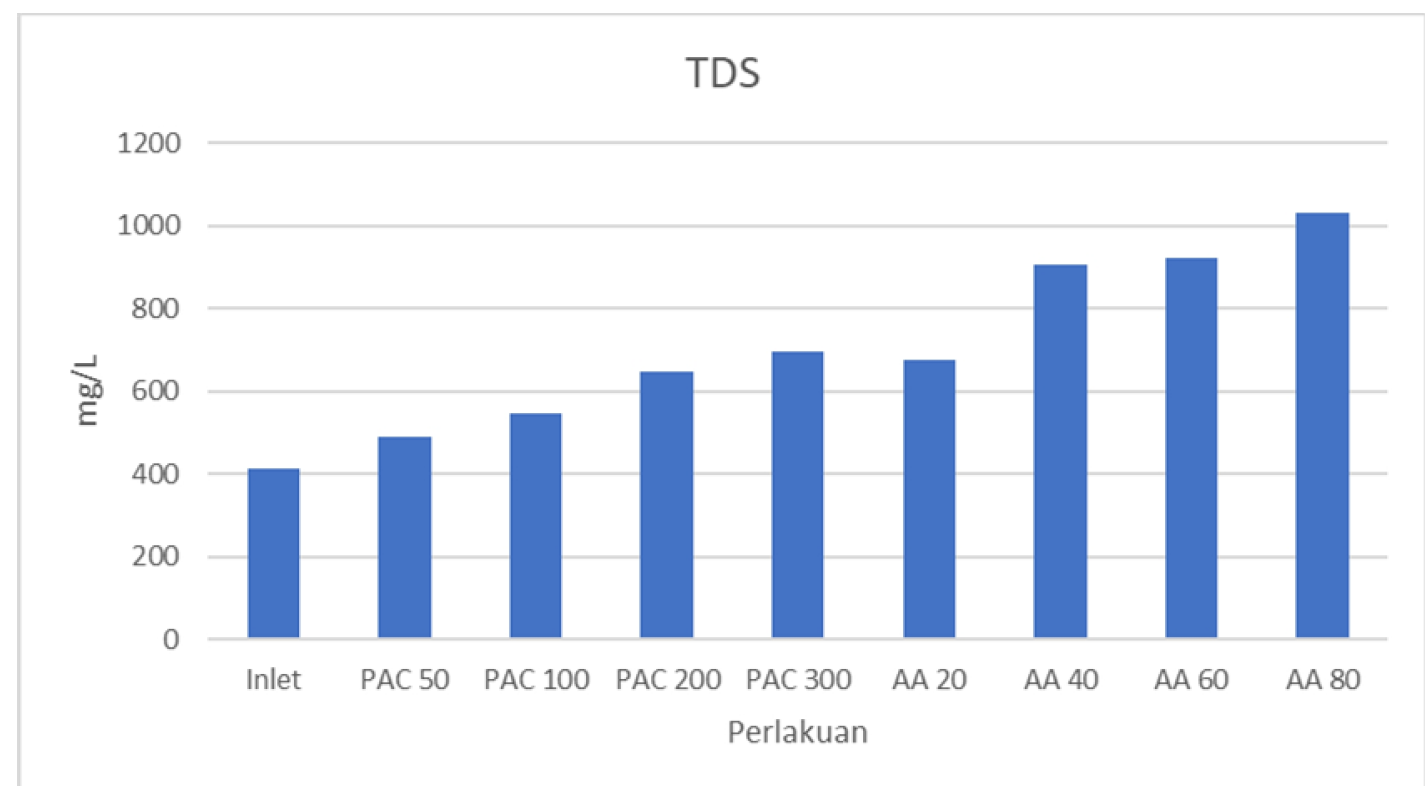

Gambar 8. Pengaruh Penambahan PAC dan AA terhadap nilai TDS dalam Air Limbah 


\section{SIMPULAN}

Hasil penelitian menunjukan bahwa penambahan PAC sebesar 50 ppm mampu menurunkan nilai kekeruhan hingga 87,2\%, TSS 83,3\%, logam Mn 70,57\% dan Fe 60,11\%. Sedangkan penambahan arang aktif 80 gram mampu mengembalikan nilai $\mathrm{pH}$ menjadi netral dan menurunkan kandungan MBAS hingga $83,62 \%$. Lebih lanjut, penambahan PAC dan arang aktif tidak berpengaruh signifikan terhadap penurunan kadar ammonia dan TDS. Hasil penelitian menunjukan penambahan PAC dapat dilakukan pada bak awal dan dikombinasikan dengan penambahan arang aktif pada bak pengolahan selanjutnya.

\section{ACKNKOWLEDGEMENT}

Ucapan terima kasih disampaikan kepada Ibu Prima Yudha Hayati selaku kepala Baristand Industri Bandar Lampung yang telah mendukung pelaksanaan kegiatan penelitian ini. Serta saudara Tri Susanto dari Baristand Industri Palembang yang telah banyak membantu penulis dalam menyusun karya tulis ini sehingga memiliki struktur pembahasan yang sesuai dengan panduan. Serta ucapan terima kasih untuk para analis laboratorium yang telah membantu melakukan pengujian.

\section{REFERENSI}

Artiyani, A., Firmansyah, N. 2016. Kemampuan Filtrasi Upflow Pengolahan Filtrasi Up Flow dengan Media Pasir Zeolit Dan Arang Aktif Dalam menurunkan Kadar Fosfat dan Deterjen Air Limbah Domestik. Jurnal Industri Inovatif, 6(1), 8-15.

Audina, M. 2017. Pengolahan Limbah Cair Laboratorium Teknik Lingkungan dengan Koagulasi dan Adsorpsi untuk Menurunkan Cod, Fe, dan Pb. Jurnal Teknologi Lingkungan Lahan Basah, 1.

BSN. 2004. Cara uji mangan (Mn) dengan Spektrofotometri Serapan Atom (SSA)-nyala. Badan Standardisasi Nasional.

BSN. 2004. Cara Uji Besi (Fe) Dengan Spektrofotometri Serapan Atom (SSA). Badan Standardisasi Nasional.

BSN. 2004. Cara uji padatan tersuspensi total (Total Suspended Solid, TSS) secara gravimetri. Badan Standardisasi Nasional.

BSN. 2005. Cara uji kadar padatan terlarut total secara gravimetri. Badan Standardisasi Nasional.

Budiman, A., Wahyudi, C., Irawati, W., Hindarso, H. 2008. Kinerja Koagulan Polu Aluminium Chloride (PAC) Dalam Penjernihan Air Sungai Kalimas Surabaya Menjadi Air Bersih. Jurnal WIdya Teknik, 7(1), 25-34.

Fadhilah, R. Y. 2018. Pengolahan Limbah Laboratorium Kimia Dengan Kombinasi Metode Elektrokoagulasi, Filtrasi dan Pengikatan Logam Dengan Asam Jawa. UIN Alauddin Makassar.

Gozan, M., Wulan, P. P., Putra, H. 2009. Peningkatan Efesiensi Penggunaan Koagulan Pada Pengolahan Air Limbah Batu Bara. Jurnal Teknik Kimia Indonesia, 8(2), 44-49.

Hidayat, G. N., Hidayat, M., Cahyono, R. B. 2019. Pengolahan Limbah Cair Carwash Dengan Proses Filtrasi dan Adsoprsi Menggunakan Arang dan Arang Aktif. Prosiding Seminar Nasional Inovasi dan Aplikasi Teknologi di Indonesia.

Mangiwa, S., Salim, I., Maryuni, A. E. 2020. Pembuatan Arang Aktif dari Tempurung Kelapa dan Aplikasinya Untuk Pengolahan Limbah Cair Tahu Tempe. Jurnal Pengabdian Papua, 4(1).

Nurhasni, Firdiyono, F., Sya'ban, Q. 2012. Penyerapan Ion Aluminium dan Besi dalam Larutan. Jurnal Valensi, 2(4), 516-525.

Nurhayati, I., Sugioto, Pertiwi, A. 2018. Pengolahan Limbah Cair Laboratorium Dengan Adsoprsi dan Pretretment Netralisasi dan Koagulasi. Jurnal Sains dan Teknologi. Jurnal Teknik KImia Indonesia, 8(2), 44-49.

Pambayun, G. S., Yulianto, R. Y., Rachimoellah, M., Putri, E. M. 2013. Pembuatan Karbon Aktif Dari Arang Tem- purung Kelapa Dengan Aktivator $\mathrm{ZnCl} 2$ dan Na2CO3 Sebagai Adsorben Untuk Mengurangi Kadar Fenol Dalam Air Limbah. Jurnal Teknik Pomitis, 2(1), 116-120.

Rahimah, Z., Heldawati, H., Syauqiah, I. 2016. Pengolahan Limbah Deterjen Dengan Metode KoagulasiFlokulasi Menggunakan Koagulan Kapur dan PAC. Jurnal Konversi, 5(2), 52-59.

Rosalina, Tedja, T., Sugiarti, S. 2016. Pengaruh Aktivitas Fisika dan Kimia Arang Aktiv Buah Bintaro Terhadap Daya Serap Logam Berat Krom. Jurnal Biopropal Industri, 7(1). 
Sembiring, M. T., Sinaga, T. S. 2003. Arang Aktif Pengenal dan Proses Pembuatannya. Medan: Fakutlas Teknik Universitas Sumatera Utara.

Sulistyanti, D., Antoniker, Nasrokhah. 2018. Penerapan Metode Filtrasi dan Adsorpsi Dalam Pengolahan Limbah Laboratorium. Jurnal Kimia dan Pendidikan. 3(2), 147-156.

Viena, V., Bahagia, Afrizal, Z. 2020. Produksi Karbon Aktif dari Cangkang sawit dan Aplikasinya pada penyerapan zat besi, mangan dan pH Air Sumur. Jurnal Serambi Engineering, 5(1), 875-882. 